\title{
CORRECTION
}

\section{Correction to: On the variability of motor-evoked potentials: experimental results and mathematical model}

\section{Charles Capaday ${ }^{1}$ (1)}

Published online: 11 October 2021

(c) Springer-Verlag GmbH Germany, part of Springer Nature 2021

\section{Correction to: Experimental Brain Research}

https://doi.org/10.1007/s00221-021-06169-7

In the original publication of the article, the author has spotted a small error in one of the equations in the MEP variance paper. It is the equation on page 4 under Fig. 1 to the right. The correct equation is given below:

$$
H(x)=\left\{\begin{array}{l}
1 \text { for } x>0 \\
0 \text { for } x \leq 0 .
\end{array}\right.
$$

The original article can be found online at https://doi.org/10.1007/ s00221-021-06169-7.

Charles Capaday

charles.capaday@ccapcable.com

1 Department of Health and Human Physiology, Motor

Control Laboratories, University of Iowa, Iowa City,

IA 52242, USA
Publisher's Note Springer Nature remains neutral with regard to jurisdictional claims in published maps and institutional affiliations. 